\title{
Socio-Demographic Problems of Labor Resource Reproduction in the North Caucasus Federal District of Russia
}

\author{
Shamil Gimbatov ${ }^{1 *}$ \\ ${ }^{1}$ Institute of Socio-Economic Research of the Dagestan Federal Research Centre of the Russian Academy of Sciences, \\ Russia \\ *Email: gimba@ list.ru
}

\begin{abstract}
The study aims to determine the regularity in forming the processes of labor resources reproduction in the North Caucasus Federal District of Russia (NCFD). The article assesses the changes in socio-economic processes in the region in recent years. The article analyses the demographic situation and its impact on the formation of the labor market in the context of changes in the structure of employment and unemployment in the North Caucasus. Conclusions are drawn about the gradual transformation of the region's reproductive potential and the growth of the social and demographic burden on the working-age population. The findings and used in the paper methods for conducting socio-demographic assessments help to give the predicted score of the dynamics of the processes of formation of social and labor sphere in the North Caucasus Federal district in the medium and long term and to determine the degree of changes in the labor potential of the region.
\end{abstract}

Keywords: Demographic Development, Labor potential, Reproduction of labor resources, Labor market.

\section{INTRODUCTION}

Socio-economic processes are influenced by many external and internal factors, often due to the region's demographic structure. The peculiarities of the formation of the demographic and human potential of the population living in the North Caucasus largely determine both the regional peculiarities of the reproduction of labor resources and the formation of labor markets and in general, the nature of the formation of social and economic processes in the region. In this regard, researchers Christa N. Brunnschweiler, Pietro F. Peretto, SimoneValentec note that "...Endogenous interactions between fertility and productivity growth can explain why and how demographic matters for macroeconomic performance even in the long run" [1].

The North Caucasus regional subjects of Russia have a relatively high proportion of younger and working-age residents. In the context of the worsening economic situation and rising unemployment, this situation increases the tension in the regional labor market and contributes, among other things, to the growth of outbound migration outside the regions of the most active part of the population.

At the same time, the dynamics of population growth in the NCFD regions, in our opinion, may begin to change in the direction of reduction in the medium term. This statement's basis is the presence of structural changes that occur in the dynamics of reproduction of the population and labor resources over the past decades [2].

First of all, this is due to the gradual change in the population's reproductive behaviour patterns and, as a result, there is a reduction in the birth rate and a change in the demographic situation. In these conditions, the problem of regional depopulation in the medium term may well become relevant for the North Caucasus, the traditional leader in terms of "birth rate" among the Russian Federation subjects.

Also, the population ageing problem is becoming more and more relevant for the North Caucasus, although this region is traditionally relatively "young" compared 
to Russia's other regional subjects. The ageing process of the population everywhere forms the features of social and economic development, changing the labor market, the social security system and the nature of consumption $[3,4]$.

There is a gradual slowdown in the dynamics of population reproduction, and, on the one hand, this should become a factor in reducing tension in the labor market in the region in the near future, but, on the other hand, in the context of deterioration in labor potential and an increase in the share of the population in older age groups, there is a possibility of the opposite process increased tension and an increase in the social burden on the population in younger age groups.

\section{ANALYSIS OF THE DEMOGRAPHIC SITUATION IN THE NCFD}

From 2000 to the present, the population of the NCFD has grown by more than 1.2 million people, while the annual rate of natural population growth is decreasing from year to year. The birth rate among the North Caucasus's urban population is almost no different from the average birth rate (total birth rate in the district's urban settlements in Russia 1.7, on average in Russia 1.6). Thus, the problem of qualitative and quantitative deterioration of the demographic situation in the coming years in some regions of the NCFD becomes quite real.

Simultaneously, the birth rate in the age group of 1524 years has increased over the past 10 years. There is a shift in the increase in the birth rate in this age group, while the proportion of births in older age categories of women decreases.

The most apparent change in population reproduction trends is seen in the analysis of the total birth rate (TBR) indicator, independent of the total population, the calculation of which involves considering only women of reproductive age (table 1$)$.
The total birth rate (TBR) shows how much on average one woman would give birth during the entire reproductive period (i.e., from 15 to 50 years) while maintaining at each age the birth rate of the year for which the indicator is calculated. Its value does not depend on the population's age composition and characterises the average birth rate in a given calendar period. The total birth rates are calculated as the sum of the age-related birth rates for the age groups from 15 to 49.

According to Table 1, there is a slight decrease in the TBR index in all the subjects of the NCFD. At the required reproducing coefficient level of at least 2.2, in most of the traditionally demographically "stable" regions of the North Caucasus, this level was not reached by the end of 2018. The only exception is the Chechen Republic. In the Republic of Ingushetia, the TBR indicator level decreased most significantly during this period.

\section{CHANGES IN THE DEMOGRAPHIC BURDEN ON THE WORKING-AGE POPULATION}

The decrease in the population's birth rate in the NCFD results in the planned reduction since 2000, the number of young people in the total population. Simultaneously, the share of the younger generation in the North Caucasus is still relatively high, and the number of people under working age in some republics of the North Caucasus reaches almost 30\%, with the average Russian level of $18 \%$.

But the process of reducing the young population begins to increase from year to year steadily. The rate of changes in the population structure indicates the formation of changes in the population's age structure to increase the share of the elderly population in the North Caucasus. Over the past twenty years, the number of people over the working age in the territories of the NCFD has been growing at a higher rate than the average

Table 1. Total birth rate in the NCFD

\begin{tabular}{|l|c|c|}
\hline & 2010 & 2018 \\
\hline Russian Federation & 1,567 & 1,579 \\
\hline North Caucasus Federal District & 1,990 & 1,836 \\
\hline The Republic of Dagestan & 1,918 & 1,855 \\
\hline The Republic of Ingushetia & 2,990 & 1,794 \\
\hline The Kabardino-Balkar Republic & 1,658 & 1,614 \\
\hline The Karachay-Cherkess Republic & 1,512 & 1,428 \\
\hline The Republic of North Ossetia-Alania & 1,835 & 1,827 \\
\hline The Chechen Republic & 3,453 & 2,598 \\
\hline The Stavropol Territory & 1,441 & 1,509 \\
\hline
\end{tabular}


in Russia. If in the country, the growth rate of the elderly population increased by 7 percentage points, then in the NCFD by $30 \%$ from 2010 to 2018 , compared to a decade earlier. Thus, the process of population ageing as a demographic phenomenon is becoming a reality for the entire Caucasus region.

For example, in the Republic of Dagestan, according to the results of the All-Russian population census of 2002 , about $60 \%$ of the population under the age of 30 was recorded [5]. By 2016, the share of the young population in the region was already $51 \%$. The share of women of reproductive age (15-49) has decreased by almost 4\% since 2010 (in the age group of $15-29$ by 6\%) (fig. 1).
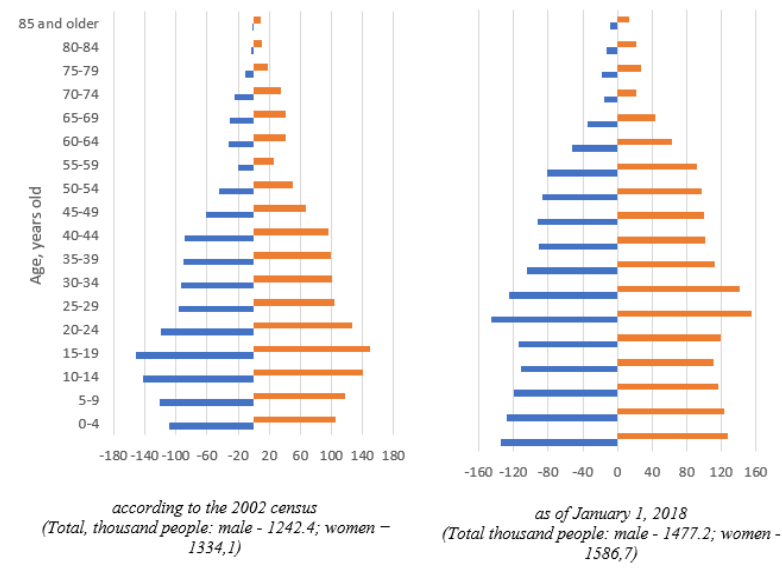

Figure 1 Age-sex pyramid (The Republic of Dagestan), thousand people.

Figure 2 shows the dynamics of changes in the demographic burden on society by the "unproductive" population, calculated using formula 1 and expressing the ratio of the number of enlarged age groups.

$\mathrm{Kd}=\mathrm{Spa}+\mathrm{Sda} / \mathrm{Swa}$

where: Sda - children (0-14 years old); Spa - elderly and old (60 years old and older); Swa - working age (1559 years old) [6].

The population's burden in retirement and "preworking" age on the working-age population has been growing over the past ten years. Simultaneously, an increase in the level of labor force participation is typical for the population in the age groups of 15-19 and 60-72 years old. The process of population ageing, which most Russia regions face, is gradually beginning to transform the population's demographic structure and the North Caucasus's reproductive potential. The results of various studies $[7,8]$ and the existing world experience suggest that the burden on the social security system, which is an inevitable and direct consequence of the ageing process of the population and the decrease in the economically active population, will increase in all subsequent years.

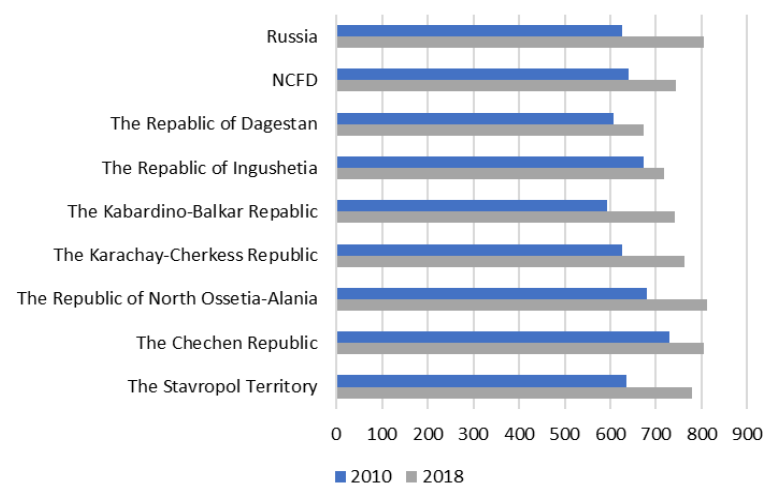

Figure 2 Demographic load factor in the Republic of Dagestan, calculated by the author according to Rosstat data [5].

\section{REPRODUCTION OF LABOR RESOURCES AND PROBLEMS OF LABOR FORCE FORMATION IN THE REGION}

In the NCFD regions in 2020, in the face of new social challenges associated with the spread of coronavirus infection, employment problems are increasing, the number of jobs decreases and the number of unemployed is growing. The number of Russian Federation subjects in which the unemployment rate of more than $10 \%$ has doubled compared to last year (from $6 \%$ to $13 \%$ according to the results for the summer of 2020). Among the lagging regions with the most challenging employment situation is the Republic of Ingushetia and the Chechen Republic with an unemployment rate of $30.7 \%$ and $21.7 \%$, respectively. In the Republic of North Ossetia-Alania and Dagestan, 16\% are unemployed, slightly less $-15.4 \%$ in Kabardino-Balkaria [9].

Currently, the Russian Federation's labor force is more than 76 million people, and in the NCFD - 4.6 million. Among the NCFD regions, almost 1.4 million people of the labor force live in the Republic of Dagestan and the Stavropol Territory. It also has the largest number of employees in absolute terms -1.2 and 1.1 million people, respectively. In the other regions of the Federal District, the total number of employees is 1.8 million.

The most "young" unemployed people live in the Republic of Dagestan and Ingushetia (about 32 years old in 2019), while the average age of unemployed people in Russia is 36.3 years old. This situation is typical not for all the NCFD subjects. In North Ossetia and the Karachay-Cherkess Republic, the unemployed' average age is higher than the national average. In this respect, the Stavropol Territory is closer to the first group of regions, where the average age is lower than the national average. The first group regions are also characterised by a remarkably high proportion of unemployed people aged $20-29$, close to almost $50 \%$ of the total unemployed. 
In 2020, out of 4.8 million unemployed people, about $22 \%$ were young people under the age of 25 , that is, more than a million young people cannot find a job (a year earlier, there were just under 800 thousand people in this category).

The number of unemployed over the age of 50 has also increased - their share in the total structure is $15.9 \%$, or slightly more than 760 thousand people (compared to less than 600 thousand in August 2019) (table 2.). The highest level of unemployment is typical for the younger population, and with each year, the concentration of unemployment among this group increases due to an increase in the share of the population in older age groups. As a result, the region's demographic potential changes, and the social burden on the working-age population, including young people, is increasing. Thus, the reduction in the share of the younger generation may become an additional factor in the growth of tension in the regional labor market, and not its reduction, as it may seem at first glance. More clearly, the situation described above is illustrated in figure 3 .
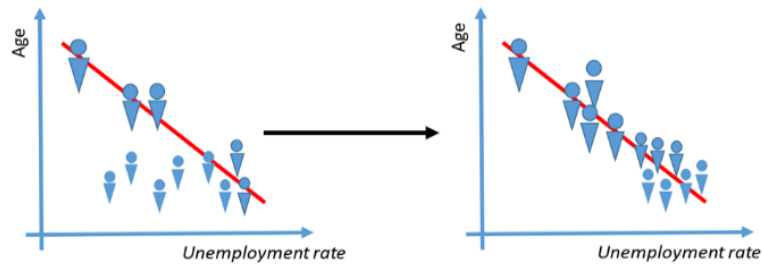

Figure 3 Characteristics of changes in the structure of the labor force in the NCFD from 2000 to 2019.

\section{CONCLUSIONS}

Against the background of changes in the dynamics of natural population growth in the NCFD, there is a change in the structure of labor reproduction, a reduction in the working-age population and an increase in the share of the elderly population. The trend of changes in the socio-demographic structure in the analysed region is mainly formed due to a decrease in the population in the "pre-working" age and an increase in the number of older working-age citizens and retirement age.

Problems in the labor market compound the ambiguity of the demographic situation in the region. Here they are the most complex among the other territories of the Russian Federation. The problems of the labor market, including unemployment in the regions of the North Caucasus are determined mainly by the characteristics of the system of reproduction of labor resources, the demographic potential and due to a combination of factors of socio-economic, political, cultural, national, geographic, demographic and geopolitical.

The social prerequisites necessary for sustained economic growth are formed in conditions of inefficient implementation of the demographic potential. Simultaneously, the management decisions are taken in regulating the social development of the region, unfortunately, are often based on generally accepted, sometimes stereotypical and distorted ideas about the demographic processes in the North Caucasus. Simultaneously, a set of measures and tools should be provided at the regional government level to contain

Table 2. Structure of unemployed persons aged 15-72 by age group, 2019

\begin{tabular}{|l|c|c|c|c|c|c|c|}
\hline \multirow{2}{*}{} & \multicolumn{3}{|c|}{ including age, years old } & \multicolumn{2}{c|}{$\begin{array}{c}\text { Average } \\
\text { age, years } \\
\text { old }\end{array}$} \\
\cline { 2 - 9 } & $15-19$ & $20-29$ & $30-39$ & $40-49$ & $50-59$ & $60-72$ & 36.3 \\
\hline Russian Federation & 3.3 & 33.7 & 25.5 & 18.6 & 15.6 & 3.3 & 37.5 \\
\hline Central Federal District & 2.1 & 31.2 & 26.8 & 17.5 & 17.4 & 4.9 & 37.9 \\
\hline North-Western Federal District & 3.4 & 29.5 & 25.6 & 18.6 & 17.1 & 5.7 & 35.8 \\
\hline Southern Federal District & 1.9 & 36.6 & 25.3 & 18.0 & 15.7 & 2.4 & 33.8 \\
\hline NCFD, including & 6.9 & 41.3 & 21.4 & 15.7 & 12.7 & 2.1 & 32.4 \\
\hline The Republic of Dagestan & 8.3 & 45.2 & 20.1 & 14.3 & 11.2 & 1.0 & 31.2 \\
\hline The Republic of Ingushetia & 2.4 & 50.2 & 29.9 & 11.7 & 5.4 & 0.5 & 37.6 \\
\hline The Kabardino-Balkar Republic & 1.0 & 29.7 & 29.2 & 19.6 & 20.0 & 0.6 & 37.1 \\
\hline The Karachay-Cherkess Republic & 1.6 & 27.2 & 30.4 & 21.5 & 18.3 & 0.9 & 38.6 \\
\hline The Republic of North Ossetia- & & & & & & & 3.9 \\
\hline Alania & 0.8 & 30.3 & 22.6 & 20.9 & 24.5 & 0.9 & 33.1 \\
\hline The Chechen Republic & 19.6 & 34.0 & 11.5 & 17.7 & 11.3 & 5.8 & 33.1 \\
\hline The Stavropol Territory & 0.9 & 50.8 & 19.2 & 13.2 & 11.9 & 4.1 & 34.3 \\
\hline Volga Federal District & 3.0 & 33.2 & 25.9 & 19.3 & 16.4 & 2.3 & 36.3 \\
\hline Ural Federal District & 3.7 & 34.6 & 26.3 & 20.6 & 12.4 & 2.5 & 35.4 \\
\hline Siberian Federal District & 3.2 & 29.3 & 26.9 & 20.8 & 16.2 & 3.5 & 37.1 \\
\hline Far Eastern Federal District & 2.3 & 33.0 & 25.6 & 19.6 & 15.6 & 3.9 & 36.8 \\
\hline
\end{tabular}


social tension in a problematic socio-demographic situation. As a result, the inefficient system of using the demographic and labor potential creates conditions for the emergence of additional barriers to the region's economic development.

\section{REFERENCES}

[1] N. Christa, Brunnschweiler, Pietro F. Peretto, Simone Valente, Wealth creation, wealth dilution and demography, Journal of Monetary Economics, 2020. DOI: https://doi.org/10.1016/j.jmoneco.2020.02.002

[2] S.M. Gimbatov, S.K. Kutayev, N.S. Gichiyev, Social and Demographic Aspects of Regional Labor Market Development, Int. Sci. Conf. Social and Cultural Transformations in the Context of Modern Globalism, The Europ. Proc. of Soc. \& Behavioural Sci. (SCTCMG 2018), 01-03 November 2018, pp. 2032-2038.

DOI: https://doi.org/10.15405/epsbs.2019.03.02.236

[3] Tony Meagher \& James Giesecke, "Population Ageing and Structural Adjustment," Australian Journal of Labor Economics (AJLE), Bankwest Curtin Economics Centre (BCEC), Curtin Business School Vol. 11(3) (2008) 227-247.

[4] A. Rishworth, S.J. Elliott, Ageing in the Developing World. International Encyclopaedia of Human Geography, Amsterdam: Elsevier, 2020, pp. 79-82. DOI: https://doi.org/10.1016/b978-0-08-102295$\underline{5.10361-0}$

[5] Demographic Yearbook of Russia-2019 [Electronic resource], Statistical collection. Retrieved from: https://rosstat.gov.ru/folder/210/document/13207 (accessed 20.10.2020).

[6] M.R. Efimova, E.V. Petrova, V.N. Rumyantsev, General theory of statistics: a textbook, Moscow: Infra-M, 2011, 416 p.

[7] Thomas Lindh, Demography as a forecasting tool, Futures Vol. 35 Iss. 1 (2003) 37-48. DOI: https://doi.org/10.1016/S0016-3287(02)00049-6

[8] S. Wang, Spatial patterns and social-economic influential factors of population ageing: A global assessment from 1990 to 2010, Social Science and Medicine. Amsterdam, Elsevier Ltd. 253 (2020) 112963.

DOI: https://doi.org/10.1016/j.socscimed.2020.112963 (accessed: 20.10.2020).

[9] Statistical portal of the ILO [Electronic resource], Statistical Collection. Retrieved from: https://ilostat.ilo.org/ (accessed 29.08.2020).
[10] Russian Statistical Yearbook-2019. [Electronic resource], Statistical collection. Retrieved from: https://rosstat.gov.ru/bgd/regl/b19 13/Main.htm (access date 29.08.2020). 